\title{
The Influence of Race on Overall Survival in Patients with Newly Diagnosed Bladder Cancer
}

\author{
Casey DeDeugd • Makito Miyake • \\ Diego Aguilar Palacios • Charles J. Rosser
}

Received: 20 March 2014 / Revised: 29 July 2014 / Accepted: 22 August 2014 / Published online: 11 September 2014

(C) W. Montague Cobb-NMA Health Institute 2014

\begin{abstract}
Background Previous studies have reported significant lower incidence yet greater risk of death from bladder cancer $(\mathrm{BCa})$ in African-Americans compared with Caucasians. In this study, the overall survival amongst African-Americans and Caucasians with BCa within the state of Florida is evaluated. Materials and Methods The Florida Cancer Data System and the Florida Agency for Health Care Administration data sets were linked on the basis of unique identifiers, which identified 28,786 patients $(27,811$ Caucasian and 975 AfricanAmericans) with newly diagnosed BCa from January 1994December 2009. Data in the database included race/ethnicity, age, smoking history, insurance status, treatment, tumor grade, tumor stage, and overall survival. Chi-square and Mann-
\end{abstract}

Electronic supplementary material The online version of this article (doi:10.1007/s40615-014-0055-x) contains supplementary material, which is available to authorized users.

C. DeDeugd $\cdot$ M. Miyake $\cdot$ D. A. Palacios $\cdot$ C. J. Rosser Section of Urologic Oncology, MD Anderson Cancer Center Orlando, Orlando, FL 32806, USA

C. DeDeugd

e-mail: casey.dedeugd@gmail.com

M. Miyake

e-mail: makitomiyake@yahoo.co.jp

D. A. Palacios

e-mail: dieguin_chivo@hotmail.com

C. DeDeugd

College of Medicine, University of Central Florida, Orlando,

FL 32827, USA

C. J. Rosser ( $\square)$

Clinical and Translational Research Program, University of Hawaii

Cancer Center, 701 Ilalo St, Rm 327, Honolulu, HI 96813, USA

e-mail: crosser@cc.hawaii.edu

C. J. Rosser

e-mail: deacdoc@aol.com
Whitney $U$ tests were used to compare variables between African-Americans and Caucasians. Survival rates were calculated by the Kaplan-Meier method while univariate effects were tested by the log-rank test, and multivariate effects were tested by Cox proportional-hazard regression model. $P$ values less than 0.05 were considered statistically significant.

Results Higher clinical stage bladder tumors including T3/4 disease $(14.5 \%$ vs. $8.0 \%, p<0.001)$, lymph node involvement $(7.3 \%$ vs. $3.4 \%, p<0.001)$, and metastatic disease (5.3\% vs. $1.7 \%, p<0.001)$, as well as higher grade disease $(60.2 \%$ vs. $48 \%, p<0.001)$ were more commonly reported in African-Americans than in Caucasians with newly diagnosed BCa. African-Americans tended to be treated with more aggressive therapies (e.g., radical cystectomy). After adjusting for all covariates, African-Americans actually had more favorable outcomes as related to overall survival $(\mathrm{HR}=0.35$, $95 \%$ CI, 0.12-0.98, $p=0.045$ ).

Conclusions Though African-Americans initially present with more aggressive $\mathrm{BCa}$, African-Americans actually have an improved overall survival compared with Caucasians. Though contrary to previous reports, our results may signify a more complex relationship between race and $\mathrm{BCa}$ outcomes and thus warrants further attention.

Keywords Black · Bladder cancer · Disparity $\cdot$ Overall survival

\section{Introduction}

Despite advances in cancer care, there is still a persistent disparity between the mortality rates of African-Americans and Caucasians with most types of cancers [1]. On average across all cancers, African-Americans have a 2.2-fold increase in developing cancer and a $20 \%$ higher mortality rate from cancer compared with Caucasians [2]. These racial disparities 
related to the incidence of cancers and deaths from cancers are evident in some of the most common cancers affecting society (e.g., lung, prostate, breast, and colorectal cancers). For breast and colon cancers, it was found that African-Americans present with these cancers at a younger age and more advanced stage than Caucasians with these same cancers [3]. Furthermore, both breast and colon cancers in AfricanAmericans are associated with a reduction in 5-year diseasespecific survival compared with Caucasians $(62.1 \%$ vs. $70.4 \%$ for breast cancer and $41.3 \%$ vs. $45.4 \%$ for colon cancer, respectively) [3]. Similarly with prostate cancer, the incidence is highest in African-Americans by nearly $50 \%$ with a corresponding twofold increase in mortality rates amongst Africans-Americans compared with Caucasians. Moreover, African-Americans presented with higher-stage prostate cancer. However, when the data were corrected for socioeconomic factors as well as stage, being of AfricanAmerican descent still was associated with a reduction in 5year survival [4]. Thus, in multivariate models, correcting for higher clinical stage and higher pathologic grade did not ameliorate this racial disparity related to survival. Additionally, this trend was seen in areas with high poverty rates and within equal access medical systems, thus illustrating that the racial disparity is not related to access to healthcare or quality of healthcare rendered [5].

In the US, an estimated 74,690 new cases of bladder cancer (BCa) were diagnosed in 2014, and an estimated 15,580 patients died of this disease in the same year [1]. The incidence of $\mathrm{BCa}$ among Caucasians is higher compared with African-Americans. It is also well established that AfricanAmericans present with higher stage and higher-grade tumors at diagnosis [6]. Furthermore, African-Americans were noted to have a $70 \%$ higher risk of cancer-related death compared with Caucasians [7]. Even when assessing survival among patients with localized disease, African-Americans possessed a significantly worse 10-year disease-specific survival compared with Caucasians [8]. In addition, results from a largescale epidemiologic study using the SEER database demonstrated that African-Americans diagnosed with early stage $\mathrm{BCa}$ have a $23 \%$ higher risk of death from the disease than Caucasians [9]. Herein, we set out to study the presenting characteristics, therapy rendered, and overall survival among African-Americans with $\mathrm{BCa}$ within the state of Florida.

\section{Materials and Methods}

\section{Study Population}

The 2011 Florida Cancer Data System (FCDS) data set was used to identify all incident cases of bladder tumors diagnosed in the state of Florida. The FCDS data set was enhanced with 2007 data linked from the Florida Agency for Health Care
Administration (AHCA) data set. AHCA maintains two databases (Hospital Patient Discharge Data and Ambulatory Outpatient Data) on all patient encounters within hospitals and freestanding ambulatory surgical and radiation therapy centers within Florida. All hospitals are required to report all discharges and outpatient encounters to AHCA since 1987. The AHCA data sets used in this study contain diagnoses and procedures performed during every hospitalization or outpatient encounter in the state of Florida, for the period 1994 2009. The comorbidity data obtained from the AHCA data set allowed for better correction of covariates. Tobacco data are self-reported at the time of cancer diagnosis, and information on duration of use was not available.

Cases in the FCDS and AHCA data sets were linked on the basis of unique identifiers. These matches were confirmed with the patient's date of birth and sex. Non-Florida residents were not included in the analysis. Self-reported racial categories included: Caucasian, African America, Asia and Other. Due to the low number of Asians, they were excluded from analysis. A total of 138,921 Caucasians with BCa and 4,461 African-Americans with $\mathrm{BCa}$ were diagnosed in the state of Florida from January 1994 to December 2009. Complete information on tumor grade and stage were available on 27,811 Caucasians with $\mathrm{BCa}$ and 975 African-Americans with BCa. These 28,786 patients comprised our study group. Orlando Health and University of Central Florida College of Medicine Institutional Review Boards granted approved this study with a waiver of informed consent.

The staging criteria used by the FCDS are consistent with the Surveillance, Epidemiology, and End Results (SEER) summary staging [10]. In this study, local staging represents disease that does not extend beyond the primary organ, whereas those having positive lymph nodes at the time of resection were classified as having regional disease. Documentation of distant metastases during the perioperative period led to classification of affected patients as having distant disease.

\section{Statistical Analysis}

Correlations between variables were made using the Chisquare and Mann-Whitney $U$ tests. Median overall survival rates were calculated by the Kaplan-Meier method. Because the FCDS collects only primary cause of death, we could only analyze overall survival and not disease-specific survival. Survival was calculated from the time of the initial diagnosis to date of last contact, or date of death, which was the time of censoring. The univariate effects of demographic, clinical, and tumor variables on survival were tested by the log-rank test for categorical values. To estimate the impact of race on survival outcomes, we used a Cox proportional hazards model, adding demographic, clinical, and treatment variables in a stepwise fashion. $P$ values less than 0.05 were considered statistically 
significant. Statistical analysis was performed with SPSS Statistical Package version 15.0 (SPSS Inc., Chicago, IL).

\section{Results}

The characteristics of the study population are shown in Table 1. The cohort included 27,811 (96.6\%) Caucasians and 975 (3.4\%) African-Americans. Among AfricanAmericans, one-third of the patients were females while, among Caucasians, one-fifth of the patients were female. Furthermore, the mean age for African-Americans with newly diagnosed $\mathrm{BCa}$ was 68 years compared with 72 years for Caucasians $(p<0.0001)$. Caucasians were more likely than African-Americans to have a history of tobacco use and to be on government insurance (Medicare or Medicaid). The most common histologic subtype of cancer was transitional cell carcinoma (TCC) present in $>92 \%$ of the AfricanAmericans and Caucasian patients; however, other histologic subtypes (e.g., squamous cell carcinoma, adenocarcinoma) were more common amongst African-Americans than Caucasians ( $7.9 \%$ vs. $3.1 \%, p<0.0001)$. Moreover, African-Americans presented with higher stage and highergrade tumors. For example, more African-Americans presented with clinical T3/4 disease than Caucasians (14.5\% vs. $8 \%$, $p<0.0001$ ), more African-Americans presented with node positive disease than Caucasians $(7.3 \%$ vs. $3.4 \%$, $p<0.0001)$, and more African-Americans presented with metastatic disease than Caucasians (5.3\% vs. $1.7 \%, p<0.0001$ ). In addition, more African-Americans presented with high grade tumors (G3) than Caucasians (60\% vs. $48 \%$, $p<0.0001)$. Since African-Americans presented with more adverse disease characteristics (e.g., high grade and high stage), it is not surprising then that the percentage of African-Americans undergoing curative surgery (e.g., cystectomy or pelvic exenteration), systemic therapy, or definitive radiation therapy was significantly greater than the percentage of Caucasians undergoing these therapies (Fig. 1). In order to further elucidate whether AfricanAmericans received more aggressive therapy, we analyzed treatments received stratified by stage of the disease and identified that more African-Americans with Ta and T1 underwent cystectomy/pelvic exenteration compared to Caucasians. However, more Caucasians underwent cystectomy/pelvic exenteration for Tis, T2, or T4 disease (Supplemental Table 1).

Figure 2, a and b, show the Kaplan-Meier plots for overall survival rates among African-Americans and Caucasians based on clinical stage, tumor grade, and histological subtypes. The difference in the univariate log-rank analysis in the overall survival curves among Caucasians and AfricanAmericans was not statistically significant $(p=0.15)$. The median overall survival rates for African-Americans and Caucasians were (16 months vs. 11 months, respectively, $p<0.001$ ). Table 2 shows the univariate and multivariate (adjusted simultaneously for all study variables) hazard ratios (HRs) for associations between demographic, clinical factors, tumor stage, and grade with overall survival. The highest HR in the multivariate analysis $(\mathrm{HR}=4.81 ; 95 \% \mathrm{CI}=2.49$ to 9.3 , $p<0.001)$ was for metastatic disease compared with nonmetastatic disease. Female gender, higher stage, higher grade, and current tobacco use were also statistically significant variables conveying a poor prognosis (i.e., reduced OS). Interestingly, public insurance and being of AfricanAmerican descent were statistically significant variables conveying a favorable prognosis (i.e., improved overall survival).

\section{Discussion}

Based on comparative data from the National Cancer Institute, Africans-Americans possess nearly half the likelihood of developing $\mathrm{BCa}$ (incidence rate 11.0 per 100,000 cases for Africans-Americans and 21.7 per 100,000 cases for Caucasians) [2], which shifts the burden of the disparity to Caucasians who possess the higher incidence of $\mathrm{BCa}$. Interestingly, despite the dramatically lower incidence of $\mathrm{BCa}$ amongst Africans-Americans, Africans-Americans have been reported to have a $23 \%$ increased in mortality from $\mathrm{BCa}$, thus an incongruence of mortality rate and incidence rate is observed that is not observed in other cancers $[2,11]$.

A SEER study showed that, in addition to higher mortality rates, Africans-Americans are also more likely to present with higher-grade bladder tumor than Caucasians as well as present with higher-stage bladder tumor than Caucasians [12]. This predilection for higher-stage and higher-grade disease at diagnosis was consistent with our results. In addition, these patients with more aggressive disease were more likely to receive curative surgery [13], which, again, was consistent with our data. Furthermore, Africans-Americans were more likely than Caucasians to have histologic subtypes other than transitional cell carcinoma of the bladder including adenocarcinoma and squamous cell carcinoma [2,14-16], confirmed in our current study. However, while controlling for these factors, we could not demonstrate a reduction in overall survival, while other investigators documented the reduction in overall survival. This may be explained by several factors. First, we noted a higher incidence of tobacco use amongst our Caucasian patients $(35.2 \%$ of Caucasians vs. $23.2 \%$ of African-Americans), which could translate into higher mortality rates. Furthermore, we had slightly higher percentage of African-Americans in our study compared with the study by Hollenbeck et al. [9] (3.4\% vs. $2.3 \%$ ). Though still a small population, our larger African American cohort may be able to fully unveil survival differences not observed in studies with 
Table 1 The characteristics of the study population

\begin{tabular}{|c|c|c|c|c|c|c|}
\hline \multirow[t]{2}{*}{ Variables } & \multirow[t]{2}{*}{ Category } & \multicolumn{2}{|l|}{ Caucasians } & \multicolumn{2}{|c|}{ African-Americans } & \multirow[t]{2}{*}{$P$ value } \\
\hline & & $N$ & $\%$ & $N$ & $\%$ & \\
\hline \multicolumn{2}{|l|}{ Total } & 27,811 & & 975 & & \\
\hline \multirow[t]{3}{*}{ Gender } & & & & & & $<0.0001$ \\
\hline & Male & 21,363 & $76.8 \%$ & 639 & $65.5 \%$ & \\
\hline & Female & 6,446 & $23.2 \%$ & 336 & $34.5 \%$ & \\
\hline Age (years) & Mean \pm SD & $72.06 \pm 11.30$ & & $68.90 \pm 12.53$ & & $<0.0001$ \\
\hline \multicolumn{7}{|c|}{ TNM (AJCC sixth edition) } \\
\hline & $\mathrm{Ta}$ & 12,427 & $44.7 \%$ & 267 & $27.4 \%$ & $<0.0001$ \\
\hline & $\mathrm{T} 1$ & 7,066 & $25.4 \%$ & 267 & $27.4 \%$ & \\
\hline & $\mathrm{T} 2$ & 4,496 & $16.2 \%$ & 253 & $25.9 \%$ & \\
\hline & $\mathrm{T} 3$ & 1,153 & $4.1 \%$ & 58 & $5.9 \%$ & \\
\hline & $\mathrm{T} 4$ & 1,084 & $3.9 \%$ & 84 & $8.6 \%$ & \\
\hline & Tis & 1,585 & $5.7 \%$ & 46 & $4.7 \%$ & \\
\hline & No & 26,867 & $96.6 \%$ & 904 & $92.7 \%$ & $<0.0001$ \\
\hline & N1-3 & 944 & $3.4 \%$ & 71 & $7.3 \%$ & \\
\hline & M0 & 27,328 & $98.3 \%$ & 923 & $94.7 \%$ & $<0.0001$ \\
\hline & M1 & 483 & $1.7 \%$ & 52 & $5.3 \%$ & \\
\hline \multicolumn{2}{|c|}{ Tumor grade (WHO1973) } & & & & & $<0.0001$ \\
\hline & G1 & 6,289 & $22.6 \%$ & 165 & $16.9 \%$ & \\
\hline & G2 & 8,175 & $29.4 \%$ & 223 & $22.9 \%$ & \\
\hline & G3 & 13,347 & $48.0 \%$ & 587 & $60.2 \%$ & \\
\hline \multicolumn{2}{|c|}{ Histological type } & & & & & $<0.0001$ \\
\hline & TCC & 26,938 & $96.9 \%$ & 898 & $92.1 \%$ & \\
\hline & $\mathrm{SCC}$ & 255 & $0.9 \%$ & 18 & $1.8 \%$ & \\
\hline & $\mathrm{AC}$ & 189 & $0.7 \%$ & 29 & $3.0 \%$ & \\
\hline & Sarcomatoid (spindle cell) carcinoma & 26 & $0.1 \%$ & 3 & $0.3 \%$ & \\
\hline & others & 158 & $0.6 \%$ & 27 & $2.8 \%$ & \\
\hline \multicolumn{2}{|c|}{ Health insurance } & & & & & $<0.0001$ \\
\hline & Private insurance & 5,711 & $20.5 \%$ & 246 & $25.5 \%$ & \\
\hline & Medicare/Medicaid & 19,415 & $69.8 \%$ & 602 & $61.7 \%$ & \\
\hline & Veterans Affairs or Military or Department of Defence & 319 & $1.1 \%$ & 12 & $1.2 \%$ & \\
\hline & Indian/Public Health Service & 16 & $0.1 \%$ & 3 & $0.3 \%$ & \\
\hline & No insurance & 619 & $2.2 \%$ & 44 & $4.5 \%$ & \\
\hline & Not recorded & 1,731 & $6.2 \%$ & 68 & $7.0 \%$ & \\
\hline \multirow[t]{5}{*}{ Smoke } & & & & & & $<0.0001$ \\
\hline & Never smoke & 7,768 & $27.9 \%$ & 347 & $35.6 \%$ & \\
\hline & History of smoke & 9,803 & $35.2 \%$ & 226 & $23.2 \%$ & \\
\hline & Current smoker & 5,316 & $19.1 \%$ & 224 & $23.0 \%$ & \\
\hline & Unknown & 4,924 & $17.7 \%$ & 178 & $18.3 \%$ & \\
\hline
\end{tabular}

Mann-Whitney $U$ test for age and chi-square test for others

$S D$ standard deviation, AJCC American Joint Committee on Cancer, $U C$ transitional cell carcinoma, $S C C$ squamos cell carcinoma, $A C$ adenocarcinoma

small African-American populations. Thirdly, the current report encompassed different study dates 1994-2009 vs. 19922002 reported by Hollenbeck [9]. These slight differences in dates may factor in evolution of therapeutic management of the patient with $\mathrm{BCa}$ (e.g., institution of neoadjuvant chemotherapy) and thus may affect the reported survival. For example, Brookfield et al. used a similar database from Florida Department of Health for analysis but reported a clear survival advantage for Caucasians. Differences between the two studies include Brookfield et al. reported on 31,100 with 
Fig. 1 Treatment options for bladder cancer stratified by race and adjusted for age, gender, socioeconomic status, tumor grade, and tumor stage

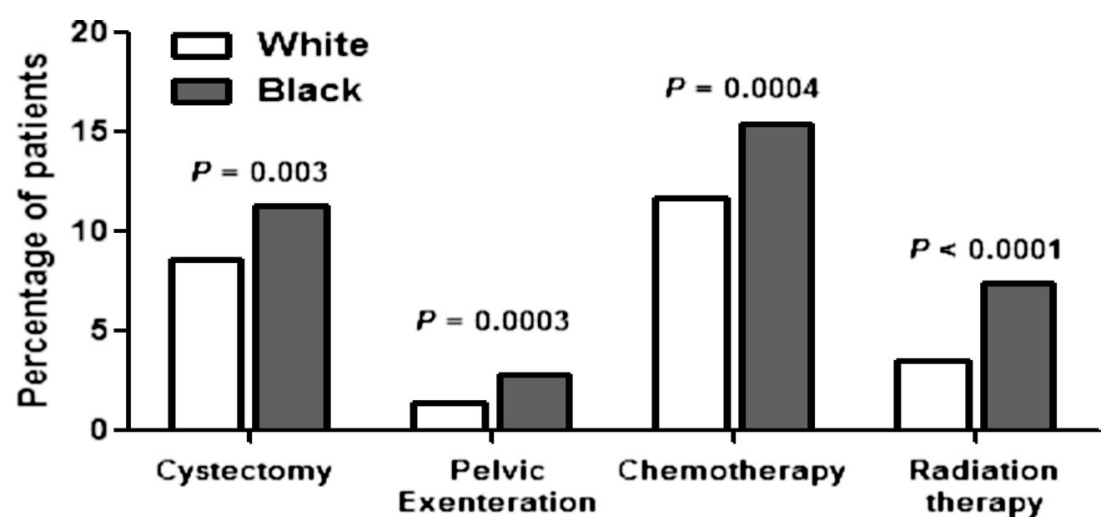

BCa from 1998-2003 in Florida, and the current manuscript reported on 28,786 patients from 1994 to 2009 [17]. The difference in the number of patients and the dates accessed could account for any differences in results. Lastly, the availability of critical confounding data (e.g., limited access to healthcare or difference in tumor biology) could not be accounted for in the current study. We are now in the process of analyzing a large bladder cancer cohort from the VA system to determine if access to healthcare services plays a role the presentation and outcomes of various racial groups. Furthermore, based on our previous molecular profiling of bladder tumors [18, 19], we are determining if AfricanAmericans and Caucasians with $\mathrm{BCa}$, matched for clininopathologic features, have different molecular signatures and thus begin to hint at different tumor biology.

Though a large study, limitations are present in this current study. First, these retrospective databases were not allinclusive and lacked critical information such as tumor recurrence and disease-specific survival. In particular, a large percentage of patients with $\mathrm{T} 2$ disease was not reported to have undergone the most common practice pattern for $\mathrm{T} 2$ disease in the US, radical cystectomy. In addition, racial identification was via self-reporting, which has its drawbacks and can introduce bias [20,21]. Furthermore, though larger than previous studies, African-Americans still comprised an extremely small proportion of our study group. Thirdly, the population dynamics of the study were limited to one geographic location, and this may not reflect the population statistics of the US. For example, between 1975 and 2009, the mortality of $\mathrm{BCa}$ in African-Americans in the US had an annual percent decline of $-1.1 \%(\mathrm{CI}=-1.2,-0.9)$ while, in Florida during the same period, the same group had an annual percent change of $-1.6 \%(\mathrm{CI}=-2.6,-1.2)$ [2]. This geographic consideration is of particular interest considering recent study reported worse outcomes for African Americans with $\mathrm{BCa}$ in various regions throughout the US.

a

Product-Limit Survival Estimates

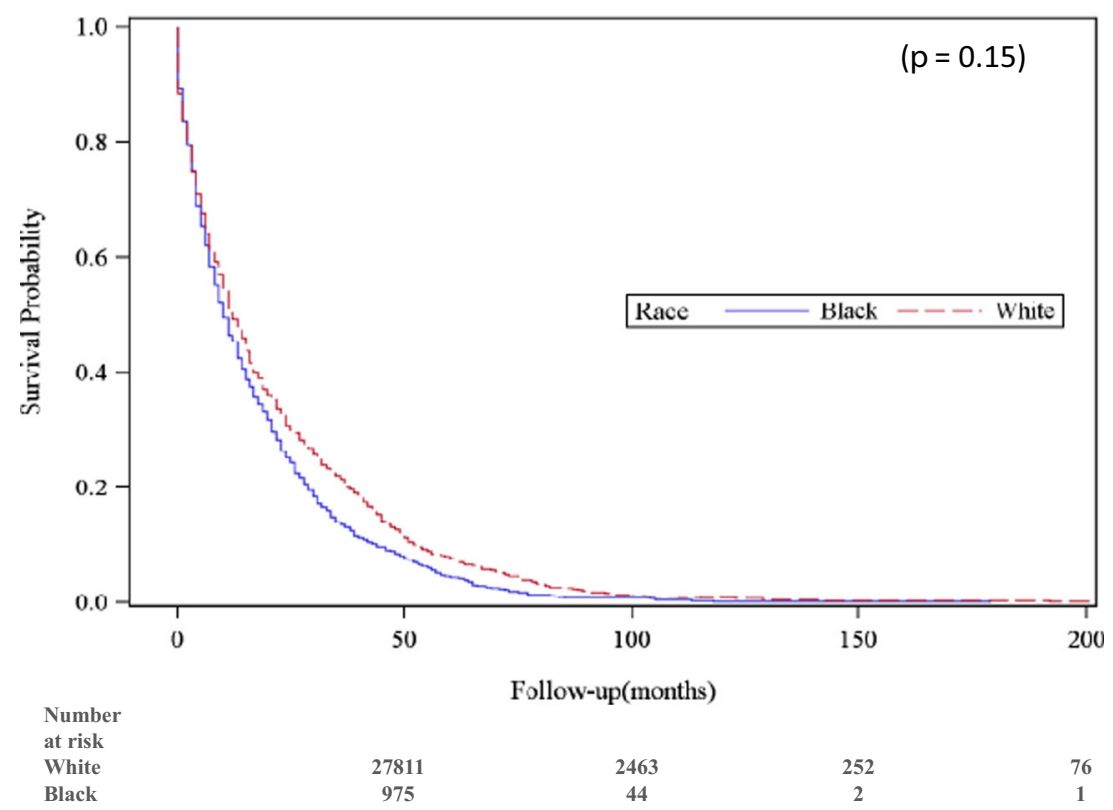

Fig. 2 Kaplan-Meier survival curves 

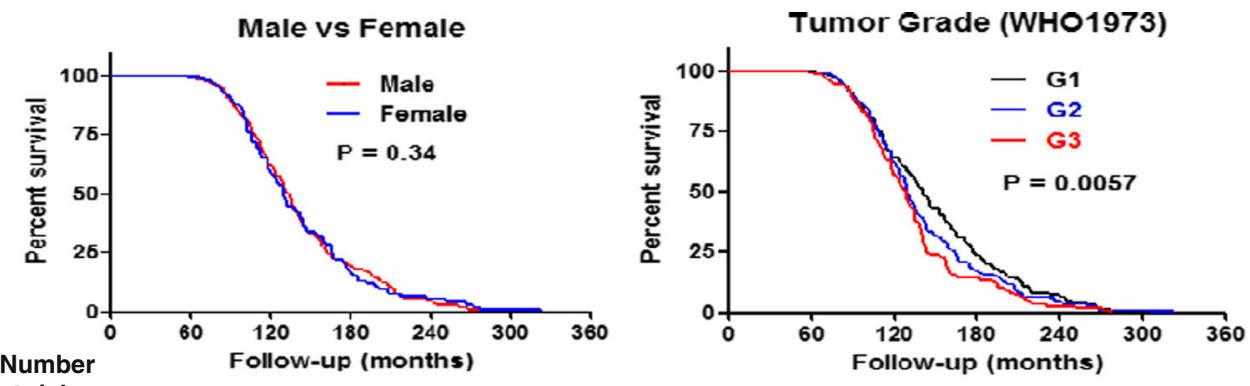
at risk

$\begin{array}{lrrrrrr}\text { Male } & 19583 & 1918 & 198 & 61 & 16 & 2 \\ \text { Female } 5942 & 589 & 56 & 16 & 6 & 2\end{array}$

$\begin{array}{rrrrrrr}\text { G1 } & 5338 & 744 & 80 & 32 & 10 & 1 \\ \text { G2 } & 7183 & 961 & 109 & 31 & 11 & 3 \\ \text { G3 } & 13006 & 802 & 64 & 17 & 4 & 1\end{array}$
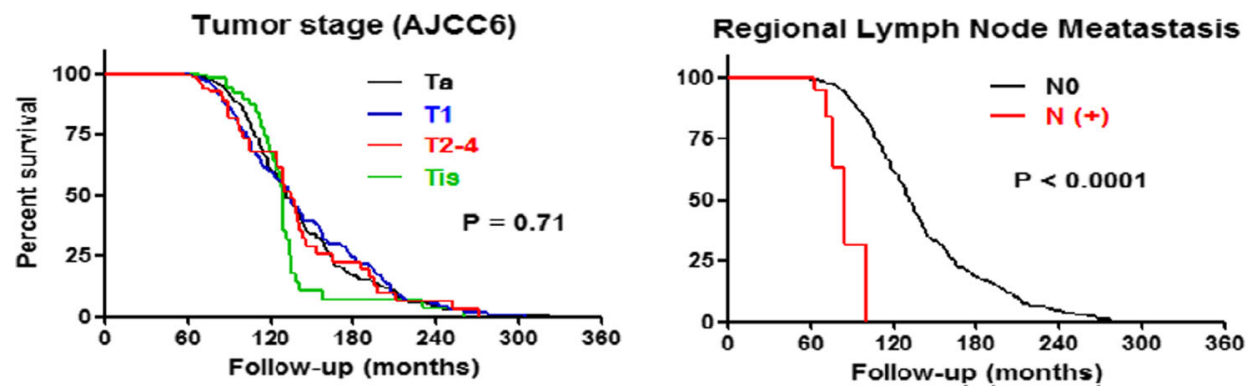

Number at risk

$\begin{array}{rrrrrrr}\text { Ta } & 10633 & 1414 & 152 & 43 & 12 & 2 \\ \text { T1 } & 6616 & 653 & 61 & 25 & 6 & 2 \\ \text { T2-4 } & 6877 & 243 & 22 & 8 & 3 & 1 \\ \text { Tis } & 1401 & 197 & 20 & 3 & 2 & 1\end{array}$

$\begin{array}{rrrrrrr}\text { N0 } & 24527 & 2486 & 253 & 76 & 20 & 3 \\ \text { N1-3 } & 1000 & 22 & 0 & 0 & 0 & 0\end{array}$
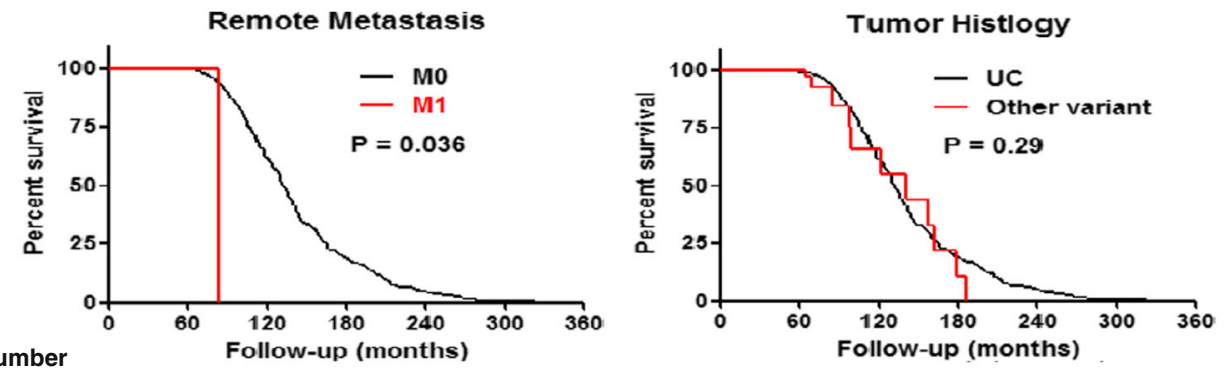

at risk

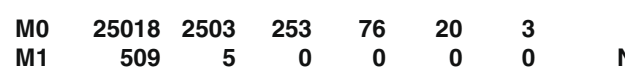

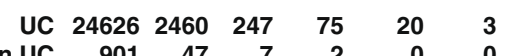

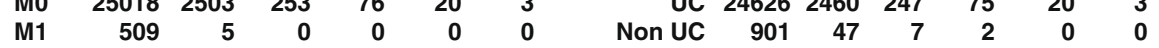
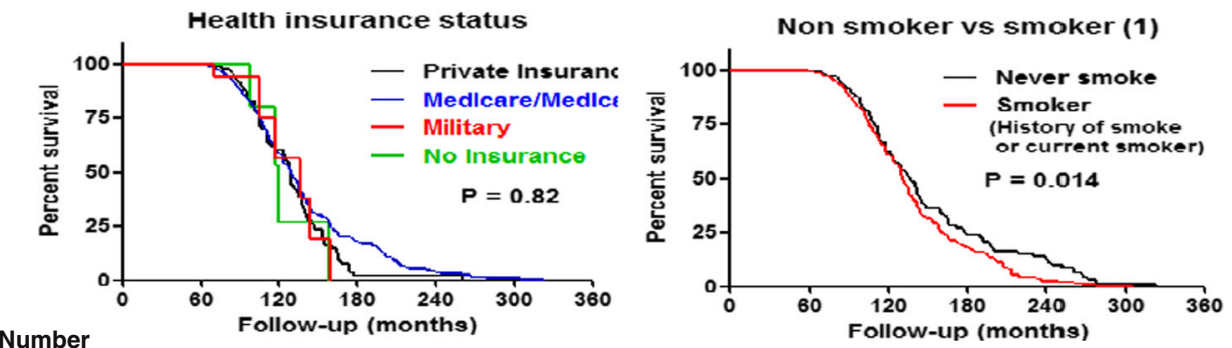

at risk

$\begin{array}{rrrrrrr}\text { PI } & 5157 & 544 & 34 & 2 & 1 & 1 \\ \text { M/M } & 17924 & 1706 & 147 & 45 & 7 & 3 \\ \text { Military } & 291 & 25 & 4 & 0 & 0 & 0 \\ \text { No } & 563 & 32 & 2 & 0 & 0 & 0\end{array}$

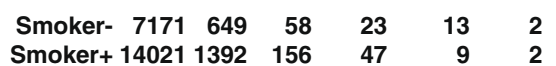

Fig. 2 (continued) 
Table 2 The univariate and multivariate (adjusted simultaneously for all study variables) hazard ratios (HRs) for associations between demographic, clinical factors, tumor stage, and grade with overall survival

\begin{tabular}{|c|c|c|c|c|c|}
\hline \multirow[t]{2}{*}{ Variables } & \multirow[t]{2}{*}{ Category } & \multicolumn{2}{|c|}{ Univariate (log-rank) } & \multicolumn{2}{|c|}{$\begin{array}{l}\text { Multivariate }{ }^{\mathrm{a}} \text { (Cox proportional-hazard } \\
\text { regression model) }\end{array}$} \\
\hline & & $\mathrm{HR}(95 \% \mathrm{CI})$ & $P$ value & $\mathrm{HR}(95 \% \mathrm{CI})$ & $P$ value \\
\hline \multicolumn{6}{|l|}{ Race } \\
\hline & Caucasians & 1 & & 1 & \\
\hline & African-Americans & $1.94(0.79-4.78)$ & 0.15 & $0.35(0.12-0.98)$ & 0.045 \\
\hline \multicolumn{6}{|l|}{ Gender } \\
\hline & Male & 1 & & 1 & \\
\hline & Female & $0.99(0.80-1.22)$ & 0.91 & $1.34(1.06-1.69)$ & 0.014 \\
\hline \multicolumn{6}{|l|}{ T stage } \\
\hline & $\mathrm{Ta}$ & 1 & & 1 & \\
\hline & $\mathrm{T} 1$ & $1.04(0.84-1.29)$ & 0.71 & $1.12(0.88-1.40)$ & 0.36 \\
\hline & $\mathrm{T} 2-4$ & $1.20(0.85-1.69)$ & 0.30 & $2.36(1.61-3.41)$ & $<0.001$ \\
\hline & Tis & $1.14(0.81-1.60)$ & 0.50 & $1(0.67-1.49)$ & 0.99 \\
\hline \multicolumn{6}{|c|}{ Regional lymph node involvement } \\
\hline & N0 & 1 & & 1 & \\
\hline & N1-3 & $583(53.88-6,305)$ & $<0.001$ & $1.29(0.59-2.80)$ & 0.52 \\
\hline \multicolumn{6}{|l|}{ Metastasis } \\
\hline & M0 & 1 & & 1 & \\
\hline & M1 & $186(1.39-2,500)$ & 0.036 & $4.81(2.49-9.30)$ & $<0.001$ \\
\hline \multicolumn{6}{|c|}{ Tumor grade (WHO1973) } \\
\hline & G1 & 1 & & 1 & \\
\hline & G2 & $1.14(0.92-1.41)$ & 0.23 & $1.11(0.86-1.44)$ & 0.34 \\
\hline & G3 & $1.41(1.11-1.79)$ & 0.005 & $1.53(1.14-2.04)$ & 0.004 \\
\hline \multicolumn{6}{|c|}{ Histological type } \\
\hline & $\mathrm{TCC}$ & 1 & & 1 & \\
\hline & Others & $1.43(0.73-2.79)$ & 0.29 & $1.68(0.88-3.20)$ & 0.11 \\
\hline \multicolumn{6}{|c|}{ Health insurance } \\
\hline & Private insurance & 1 & & & \\
\hline & Medicare/Medicaid & $0.83(0.68-1.17)$ & 0.40 & $0.54(0.41-0.71)$ & $<0.0001$ \\
\hline & Veterans Affairs of Military or Department of Defence & $1.11(0.50-2.79)$ & 0.82 & $0.81(0.26-2.59)$ & 0.73 \\
\hline & No insurance & $1.00(0.36-2.79)$ & 1.00 & $0.80(0.22-1.86)$ & 0.33 \\
\hline \multicolumn{6}{|l|}{ Smoke } \\
\hline & Never smoke & 1 & & 1 & \\
\hline & History of smoke & $1.26(1.01-1.58)$ & 0.044 & $1.11(0.88-1.40)$ & 0.39 \\
\hline & Current smoker & $1.36(0.99-1.82)$ & 0.057 & $1.41(1.06-1.87)$ & 0.018 \\
\hline
\end{tabular}

$H R$ hazard ratio, $C I$ confidence interval, $T C C$ transitional cell carcinoma

${ }^{a}$ Adjusted for age and major interventions for treatment

In the current study, we continue to add to the body of literature that reports that (a) African-Americans present with higher-stage and higher-grade $\mathrm{BCa}$ and (b) AfricanAmericans present with more non-transitional cell carcinoma histologic subtypes of $\mathrm{BCa}$. However, we could not validate after adjusting for important covariates such as age, tumor stage, tumor grade, treatment rendered, health insurance, and tobacco history that there is a reduction in overall survival in African-Americans with $\mathrm{BCa}$ compared with Caucasians with
BCa. Though contrary to previous reports, our results may signify a more complex relationship between race and $\mathrm{BCa}$ outcomes and thus warrants further attention.

Acknowledgements None

Conflict of Interests Casey DeDeugd, Makito Miyake, Diego Aguilar Palacios, and Charles J. Rosser declare that that they have no conflict of interest. 
Informed Consent All procedures followed were in accordance with the ethical standards of the responsible committee on human experimentation (institutional and national) and with the Helsinki Declaration of 1975, as revised in 2000. A waiver of informed consent was obtained from our intuitional IRB.

\section{References}

1. Siegel R, Ma J, Zou Z, Jemal A. Cancer statistics. CA Cancer J Clin. 2014;64:9-29.

2. National Cancer Institute. State cancer profiles. http:// statecancerprofiles.cancer.gov/micromaps/. Accessed 2 Feb 2011.

3. Breslin TM, Morris AM, Gu N, et al. Hospital factors and racial disparities in mortality after surgery for breast and colon cancer. J Clin Oncol. 2009;27(24):3945-50.

4. Hoffman RM, Gilliland FD, Eley JW, et al. Racial and ethnic differences in advanced-stage prostate cancer: the Prostate Cancer Outcomes Study. J Natl Cancer Inst. 2001;93(5):388-95.

5. DeLancey JO, Thun MJ, Jemal A, Ward EM. Recent trends in BlackWhite disparities in cancer mortality. Cancer Epidemiol Biomarkers Prev. 2008;17(11):2908-12.

6. Jacob BL, Montgomery JS, Zhang Y, et al. Disparities in bladder cancer. Urology Oncology: Seminars and Original Investigations. 2012;30:81-8.

7. Bach PB, Schrag D, Brawley OW, et al. Survivals of blacks and whites after a cancer diagnosis. JAMA. 2002;287:2106-13.

8. Lee CT, Dunn RL, Williams C, et al. Racial disparity in bladder cancer: trends in tumor presentation at diagnosis. J Urol. 2006;176:927-34.

9. Hollenbeck BK, Dunn RL, Ye Z, Hollingsworth JM, Lee CT, Birkmeyer JD. Racial differences in treatment and outcomes among patients with early stage bladder cancer. Cancer. 2009;116(1):50-6.

10. SEER Cancer Statistics Review; Cancer of the urinary bladder. 2011 http://seer.cancer.gov/statfacts/html/urinb.html. Accessed 11 March 2013.
11. Galsky MD, Hall SJ. Bladder cancer: current management and opportunities for a personalized approach. Mt Sinai J Med. 2010;77(6): 587-96.

12. Yee DS, Ishill NM, Lowrance WT, Herr HW, Elkin EB. Ethnic differences in bladder cancer survival. Urology. 2011;78(3): 544-9.

13. Miller DC, Saigal CS, Litwin MS. The demographic burden of urologic diseases in America. Urol Clin N Am. 2009;36(1):11-27.

14. Prout Jr GR, Wesley MN, McCarron PG, et al. Survival experience of black patients and white patients with bladder carcinoma. Cancer. 2004;100(3):621-30.

15. Madeb R, Messing EM. Gender, racial and age differences in bladder cancer incidence and mortality. Urology Oncology: Seminars and Original Investigation. 2004;22:86-92.

16. Underwood III W, Dunn RL, Williams C, et al. Gender and geographic influence on the racial disparity in bladder cancer mortality in the US. J Am Coll Surg. 2006;202:284-90.

17. Urquidi V, Goodison S, Cai Y, Sun Y, Rosser CJ. A candidate molecular biomarker panel for the detection of bladder cancer. Cancer Epidemiol Biomarkers Prev. 2012;21(12):2149-58.

18. Rosser CJ, Liu L, Sun Y, Villicana P, McCullers M, Porvasnik S, et al. Bladder cancer-associated gene expression signatures identified by profiling of exfoliated urothelia. Cancer Epidemiol Biomarkers Prev. 2009; 18(2):444-53.

19. Brookfield KF, Cheung MC, Gomez C, Yang R, Nieder AM, Lee DJ, et al. Survival disparities among African American women with invasive bladder cancer in Florida. Cancer. 2009;115(18): 4196-209.

20. Parra EJ, Marcini A, Akey J, Martinson J, Batzer MA, Cooper $\mathrm{R}$, et al. Estimating African American admixture proportions by use of population-specific alleles. Am J Hum Genet. 1998;63: 1839-51.

21. Burchard EG, Ziv E, Coyle N, Gomez SL, Tang H, Karter AJ, et al. The importance of race and ethnic background in biomedical research and clinical practice. N Engl J Med. 2003;348: $1170-5$. 